\title{
Thoughts and Suggestions on Undergraduates Innovations Experiment Project*
}

\author{
Jinjin Liang \\ School of Mathematical Sciences \\ Xi'an Shiyou University \\ ShaanXi, Xi'an \\ myonlyonly@126.com \\ Jiangang Wang \\ School of Mathematical Sciences \\ Xi'an Shiyou University \\ ShaanXi, Xi'an \\ rabbit-wjg@qq.com
}

\author{
Xiaoqun Sun \\ School of Mathematical Sciences \\ Xi'an Shiyou University \\ ShaanXi, Xi'an \\ 409802000@qq.com \\ Haojiang Cai \\ School of Mathematical Sciences \\ Xi'an Shiyou University \\ ShaanXi, Xi'an \\ imagic725@163.com
}

\begin{abstract}
Scientific research and implementing ability are the fundamental methods for cultivating talents. Undergraduates participate in the research and practice are the fundamental principle of teaching. Undergraduates innovations experiment project follows the principle of interest driven, independent practice, focusing on the process, it pays attention to training students' ability of innovation and practice. This paper discusses the problems from three aspects: the project selection, the role of the faculty adviser, and the innovation skill training; it also puts forward the suggestions: combining the selection of the innovation program with the course, the faculty adviser gives the necessary assistance and timely instruction to help students, and cultivate the students' subjective initiative.
\end{abstract}

Keywords—scientific research; implementing ability; practice; innovations; skill training; subjective initiative

\section{INTRODUCTION}

In the current knowledge economy society, how to create knowledge through learning becomes more and more important. The future education should promote the students to learn in the course of "hand in hand". As the national construction of the talent reserve, the quality of the college students has a very important impact on country's future development. For a long time, educators pay more attention to students' physical quality, the knowledge reserve, person's ability, thus cultivate a batch of students with solid reserve knowledge; but educators did not pay enough attention to cultivate the work ability of college students, resulting in college students seriously insufficient of innovation consciousness, innovation ability, lacking of practical ability and practical ability [1]. This does not meet the strategic needs of building an innovative country.

In 2007, the Ministry of education implemented the national innovation experiment program for university

This paper is supported by high level college construction of Xi' an shiyou University. students, identified the list of the accepted first batch of funded 60 universities. Since then, hundreds of colleges and universities accept the projects funded one after another so far. Each year about 4500 students accept the project sponsored by the Ministry of education, has made certain achievements. Different city and colleges also continue to carry out the funding of the innovative experimental program for undergraduates, including innovative training program, entrepreneurship training programs and entrepreneurial practice project, in order to provide the innovative experiment platform for more students. The innovative experimental program for undergraduates follow the principle of "interest driven, independent practice, emphasis on process", aims to explore and establish the teaching mode with issues and topics as the core, advocate the undergraduate students as the main body of innovation experiment reform, mobilize the students' initiative, enthusiasm and creativity, further to enhance the students' ability of innovation and experiment.

\section{CONSIDERATION AND SUGGESTION ON THE INNOVATIVE EXPERIMENTAL PLAN FOR COLLEGE STUDENTS}

As a major reform initiative to promote the innovative talents cultivation of the Ministry of education, the national college students' innovation experiment program is implemented for the first time in the national level, directly face the establishment of university students' innovation training project. It is an important part of the higher school undergraduate teaching quality and teaching reform project. The purpose of an innovative program is to create an atmosphere for students to study, to get into the scientific research, and to discuss and complete the project. The implementation of the process is more important than the results. Focuses on cultivating the finding problem ability, analysis ability, problem solving ability and communication 
ability of the students; this project stimulate students' creative thinking and innovation awareness, form an atmosphere of innovation education in the campus, construct the innovative education culture. Students gradually master methods of thinking and solving problems, and enhance the ability of innovation and practice

\section{A. Secleting the Project}

Selecting the projects is essential for the acceptance of the innovation project. Most of the questions come from college students. In other words, a considerable part of the students have a certain sense of innovation; but due to the limitations of its own accumulation of knowledge and learning ability, it is difficult for college students to grasp the dynamic hot point in the forefront of the latest development in this subject, and the horizontal linkages of relevant subjects knowledge, so that the innovation and design rationality is limited for the project [2].

Since most of the students are sophomores who attend the innovation and entrepreneurship training programs, they need to study multi basic courses and professional courses when they are freshman, so leaving less spare time. The interest in some studies arises and stays in the hazy understanding of the status when they are sophomores. Lacking of scientific research experience, these students can not talk about whether there is a clear plan to the study content, never to ensure the successfully development of the project.

Students can choose to participate in innovative training program, entrepreneurship training program and entrepreneurial practice based on their expertise and hobbies. Innovative training program is the individual or groups of undergraduates, independently complete works such as designing the innovative research project, preparing the project conditions and implementation, writing research report and exchanging academic achievements under the guidance of a mentor. Entrepreneurship training programs is the undergraduate team under the guidance of a mentor; participate in the enterprise practice, writing business reports and other work. Each student of the team play a more specific role in the process, through the preparation of a business plan, carry out feasibility study and simulation on operation of enterprises in the implementation of the project. Entrepreneurship practice project is the students teams, under the guidance of the common in the school and enterprise mentors, put forward a innovative products or services with the results of preliminary innovative training program (or innovative experiment), as a basis to carry out practical activities of starting.

For students attending the innovative training program, they can choose the teachers in relevant domains of interest in scientific research, according to their own knowledge accumulation, learn algorithm design, cultivate the ability of scientific research and programming. In this way, they can quickly enter the state of science and research on the one hand, and they can also ensure the successfully operation under the guidance of the leading experts when the difficulties encountered on the other hand. This lay a solid foundation for the future research work. For students attending the entrepreneurship training programs and the entrepreneurship practice project, they can select the instructor in related fields, by combining their expertise to the general direction of employment. On the one hand, this helps improve the design of the plan, inspection plan rationality, weigh the feasibility. On the other hand, this recommends students to the relevant enterprises to practice. During the process of enterprise practice, some of the problems can be found existing in the enterprise; even mass production can be produced by solving the problems encountered. This injects new vitality into the enterprise, and provides the students employment opportunities in the future.

\section{B. Role of the Faculty Adviser}

The faculty adviser should be equipped for the students participating in the undergraduate innovative experiment plan. Starting from the selection of project to the end of the process, the faculty adviser should try his best to ensure the smooth development and implementation of the project, cultivate the students' innovative thinking and innovative practice ability. The overall implementation of the innovative experimental program for undergraduates is a rare opportunity for the teachers and students, it not only produce beneficial changes to the traditional education thought and also produce reasonable and efficient management to the student.

As a guiding teacher, the responsibility is to help the students to start from the concrete work. During the guidance process of the students' creative practice, we must play a good supporting role, avoid by all means "hands-on" and "over-due"; we should arrange their innovation learning and practice step by step according to the specific circumstances of the students [3]. Necessary guidance and efficient help should be provided to students when needed, so that they can significantly improve related skills according to the schedule in different phases in the practice of innovation project. Only in this way, can the students feel the fun, the sense of challenge self achievement, from the innovation projects; thereby enhance the consciousness of defying conventional and continually innovation, the perseverance of completing project tasks.

The construction of a creative and innovative teaching staff is the basic guarantee for the cultivation of innovative talents. "Teachers' creative is the first principles to enable students to have creative". In innovative education, teachers play a major role. If there is no innovation of teachers, it is difficult to cultivate the innovation of talent [4]. Practice has proved that only the innovative teachers takes on the important task of education innovation and innovation personnel training. According to the situation of distance education, the so-called innovative teachers are referred to those with innovative ideas, innovative ability and innovative personality, and flexibility in the use of a variety 
of educational methods, so as to discover and cultivate innovative talents. It is a must to optimize the quality of the teachers, to strengthen the training, actively carry out the education research, catch the opportunity to realize the training focus of the teacher and the transformation of the operation mechanism in teaching and research, thus provide the innovation ability of teachers' education.

\section{Innovative Skills Training}

Students participating in the program should have a strong interest in scientific research or invention. By interest driven, students independently complete the experimental process under the guidance of a mentor. They independently complete the experiment and management; they focus on the implementation process of the innovative experiment project. Emphasizing the implementation process of the project, students harvest the innovative thinking and innovative practice. This requires that teachers should pay attention to the cultivation of students' creative skills in the ordinary teaching.

The cultivation of creative skills needs to be inspired and guided by the specific factors. However, inspiration is often short-lived, at this time if there is a strong creative skills, it will make the inspiration to become a reality. Most innovation inspiration resulted from real life; the innovation ability can be improved through participating in social practice, research and investigation, carry out some real work, scientific and technological innovation activities.

However, innovation is not a simple "packaging", it reflects a high level of capacity, which needs a variety of basic capabilities as the foundation [5]. To have a rather strong innovation ability, college students should have a strong comprehensive ability, especially the observation ability, analysis ability and problem solving ability, the independent thinking and learning ability. It is obtained by continuously thinking and learning.

From the beginning when college students enter the school, colleges and teachers can promote the college students' innovative program. Let the students be well prepared, actively acquire information, and pay attention to accumulate knowledge in the usual study. When teaching in the professional courses and basic courses, teachers can penetrate the thinking and methods of scientific research. For example, in addition to the professional courses in the classroom teaching, teachers can add discussion courses to the seminar. In this way, a simple course will require students to spend a considerable amount of time and energy to consult the literature, write their own independent design experiments and research reports or papers. Again, in the basic course of linear algebra, mathematics learning, teachers can introduce the modeling thought, this help improve the learning interest, and the boring mathematical knowledge can be linked with the specific practical problems through the carrier of the mathematical modeling.

Mathematical modeling is a kind of thinking method to solve practical problems by using mathematical knowledge. Some knowledge in the teaching process can be designed using mathematical model; these models are interesting and easy to understand for students. During the process, we guide students to solve these problems, through the establishment of mathematical models from the aspect of new "invention". This "invented" knowledge, to teachers of course is not a new invention, but for students it is new. It let the student experience the joy with the existing knowledge to solve practical problems. For example: in the teaching of higher mathematics, the continuity of the functions and the modeling problem of chairs smooth on the ground can be tightly connected. In the teaching of linear algebra group, it is appropriate to add network circuit in terms of the mathematical model and computer graphics processing model, such as the thought of linear transformation can be extended to the thought of equal angle transform in mathematical physics curriculum. This greatly broadens students' horizons.

\section{CONCLUSIONS}

College Students' innovative pilot projects focus on the cultivation of students' practical ability and innovative ability. It is an important part of the undergraduate teaching quality and teaching reform project in Colleges and universities. National, province, school all give attentions and supports. For the problems encountered in the process of project selection, role of the faculty adviser and innovative skills training in the implementation of undergraduate innovative experiment project, we give solutions. We point out that the selection of appropriate topics and guidance teachers should be based on the students' interests and expertise; the guidance teachers in the project should do a good guidance role; the training of innovation skills should start from the classroom by penetrating the research consciousness.

\section{ACKNOWLEDGEMENT}

The author sincerely thanks the reviewers for the hard work, and thanks the dean of the Xi'an Shiyou University and the School of science for the final support.

\section{REFERENCES}

[1] Chen Yang, Yan Da-yuan,Ming Dao-fu. "Pratice and Thoughts on the Implementation of the National College Students Innovation Experiment Program" Journal of Beijing Institute of technology (Social Sciences Edition), vol. 11, pp. 93-95, April 2009.

[2] Chen Xi, Feng Xi-ping. "Thoughts on National college gradates innovation experiment program", Northwest medical education, vol. 17, pp.12-13, Febl 2009.

[3] Yang Kun, Huang Jin, Hu Qiang, Li Yong. "Practice and Exploration of the Innovative Experimental Program for Undergraduates", Jiao xue shi jian yan jiu, vol. 1, pp. 191-193, Sep. 2014.

[4] Qiao Lian-quan. "The Present Situation and Reflections on the Undergraduate Innovation Experiment Program in Research Universities of China", Journal o f Higher Education, vol. 32, pp. 81-87, Mar. 2011.

[5] C. A. Merkel. "Undergraduate rresearch at six rresearch uuniversities [EB/ OL]. http://ugr.tamu.edu/opportunities-1/ faculty/ undergraduate research, Jan. 2011. 